WellBeing International

WBI Studies Repository

1977

\title{
Social Communication in Canids: Evidence for the Evolution of a Stereotyped Mammalian Display
}

Marc Bekoff

University of Colorado

Follow this and additional works at: https://www.wellbeingintlstudiesrepository.org/acwp_ena

Part of the Animal Studies Commons, Comparative Psychology Commons, and the Other Animal Sciences Commons

\section{Recommended Citation}

Bekoff, M. (1977). Social communication in canids: Evidence for the evolution of a stereotyped mammalian display. Science, 197(4308), 1097-1099.

This material is brought to you for free and open access by WellBeing International. It has been accepted for inclusion by an authorized administrator of the WBI Studies Repository. For more information, please contact wbisr-info@wellbeingintl.org.

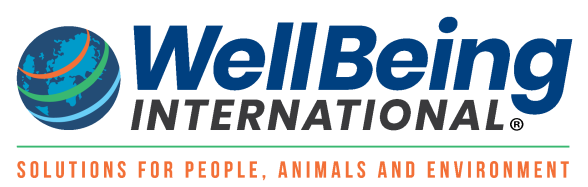




\title{
Social Communication in Canids: Evidence for the Evolution of a Stereotyped Mammalian Display
}

\author{
Marc Bekoff \\ University of Colorado
}

\begin{abstract}
The variability in the duration and form of the canid play bow was studied in infant coyotes, wolves, wolfdog hybrids, beagles, and adult free-ranging dogs. Both duration and form showed marked stereotypy. It appears that the role of this context-specific social signal in the communication of play intention has been fostered by selection for "morphological" stereotypy.
\end{abstract}

Despite a history of considerable interest in animal social communication (1-3), few data are available on the "anatomy" or form of signals that are used. Indeed, one of the basic concepts of classical ethology, the "fixed" action pattern, rarely has been studied quantitatively (4-7). The form of visual displays has been studied quantitatively in invertebrates, lizards, and birds (4-7); however, there are very few data for mammalian displays $(8,9)$. In addition, little is known about the ontogeny of mammalian displays $(2,8$, 10). Available evidence has demonstrated clearly that some social signals show phenotypic plasticity and that selection can shape various components (for example, duration, inter-act interval, form, sequence) of a signal or set of signals $(1-7,11-13)$. In cases in which it would be important to reduce ambiguity in the communicated message, selection could operate on signal structure (as with any other morphological structure) to reduce variability. Furthermore, it also is possible for certain signals to be restricted to specific contexts. Below I report the results of an analysis of a specific canid "play invitation" signal, the bow $(14,15)$, that shows marked stereotypy both in duration and form.

The bow is an easily recognized canid social display (Fig. 1). When performing this motor act, the animal crouches on its forelimbs and remains standing on its hind legs. The bow is infrequently observed outside the context of play (15). The bows of the following groups of animals were analyzed: 12 infant coyotes, Canis latrans; 4 infant wolves, C. lupus; 4 infant wolf-malamute hybrids; 13 infant beagles, C. familiaris; and 16 free-ranging domestic dogs over 1 year of age (age verified by owners). Infants were observed from about 20 to 90 days of age in a variety of situations. Some of the infants were hand-reared, and periods of social interaction with conspecific age-mates were limited only to times when observers were present. For these infants, it was possible to record the first occurrence of the bow during social interaction. Other infants were mother-reared in seminatural conditions, and observations commenced when they emerged from the den that their mother had dug or from the den box that I provided. The freeranging dogs were observed on the campus of Washington University (St. Louis, Missouri) and in and around Nederland, Colorado. 
Table 1. The variability, expressed as the coefficient of variation (\%), of bows performed at the beginning of and during play bouts by three canid species. Form was measured on a grid system (see text and Fig. 1). The number on the left of the slash $(I)$ refers to bows that were performed at the beginning of play bouts, and the number on the right of the slash refers to bows that were performed during an on-going interaction. The differences between the coefficients of variation for bows performed at the beginning of and during play bouts were tested for statistical significance by using the "c" statistic (17); see footnotes. The bows performed by the infant coyotes showed significantly less variability in form than those performed by the other groups. For example, when the bows of the coyotes were compared with those of the wolves, the differences were highly significant (for bows performed at the beginning of a bout, $c=3.46$, d.f. $=169, P<$ .001 ; for bows performed during a bout, $c=3.04$, d.f. $=119, P<.01$ ). The significance of play signals for highly aggressive infant coyotes when compared with less aggressive infant wolves and beagles is discussed in (15) and (23).

\begin{tabular}{|lccc|}
\hline & & \multicolumn{2}{c|}{ Coefficient of variation (\%) } \\
\cline { 3 - 4 } Species & Number of bows & Duration of bows & Form of bows \\
\hline Coyotes $(N=12)$ & $73 / 57$ & $9.68 / 13.79^{*}$ & $5.49 / 6.55 \dagger$ \\
Wolves + wolf-dog hybrids $(N=8)$ & $98 / 64$ & $10.53 / 11.43 \dagger$ & $8.02 / 9.77 \dagger$ \\
Beagles $(N=13)$ & $116 / 81$ & $15.15 / 18.75 \ddagger$ & $9.71 / 10.57 \dagger$ \\
Adult dogs $(N=16)$ & $153 / 114$ & $21.87 / 28.13 \S$ & $10.87 / 12.70 \dagger$ \\
\hline
\end{tabular}

${ }^{*} \mathrm{C}=2.70$, d.f. $=128, P<.01$

$\dagger P>.05$

$\ddagger \mathrm{c}=2.20$, d.f. $=195, P<.05$

$\S \mathrm{c}=2.79$, d.f. $=265, P<.01$

Fig. 1. A bow performed by the dog on the right. Form was measured on a grid system as the vertical displacement of the shoulders (a; see text). Lie of the hair around the shoulder was a reliable marker.

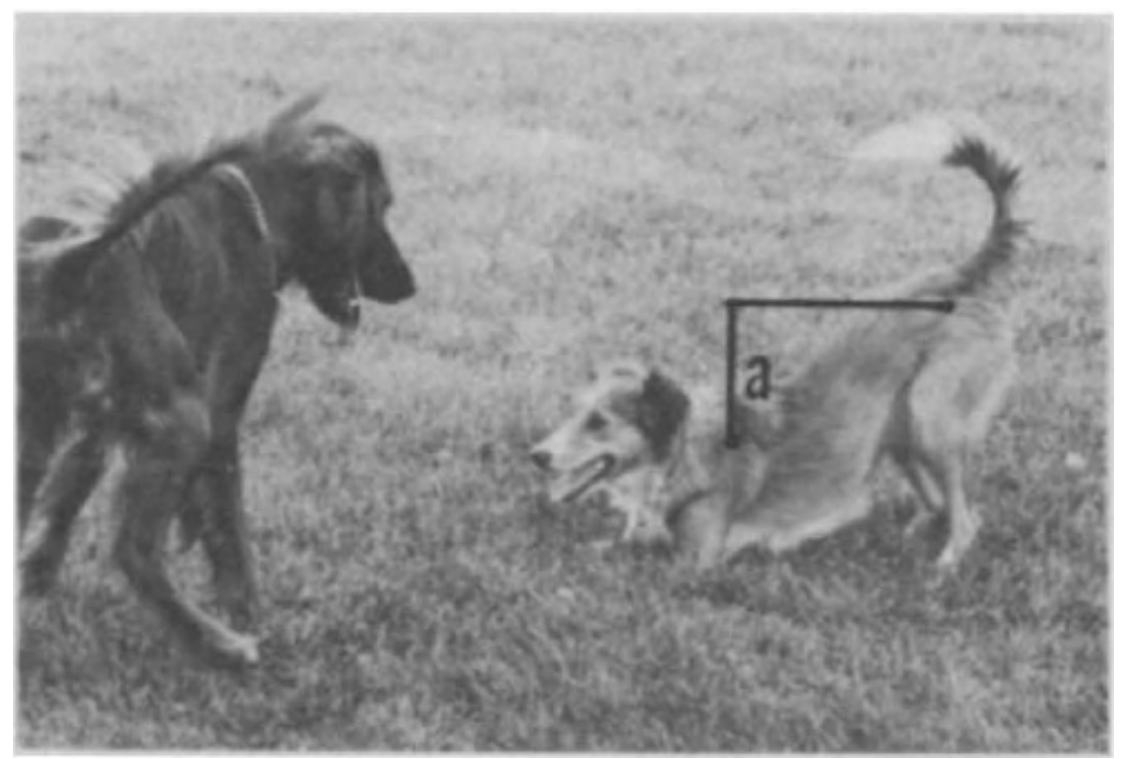

Animals were photographed with a super-8 or 16-mm movie camera (film speed, 64 frames per second). Films were analyzed with a single-frame analyzer. Camera speed was checked prior to each analysis to correct for possible error. Both duration and form were measured for bows that occurred in the beginning 
of a sequence (that is, the first act) and during a sequence. Duration was measured by counting the number of frames during which the individual remained crouched. The number of frames was then multiplied by 0.0156 second ( $=1$ frame) to convert to a measure of time. Means, standard deviations, and coefficients of variation were then calculated. Form was measured as declination of the shoulders relative to standing height on a grid system (Fig. 1, a). In order to standardize for individual differences in size as well as for changes in size with age, the height of the body at the shoulders was divided by 10 , and a grid system of ten equal segments was used. Each grid unit was divided into fourths. Two observers independently took measures for each data point, and measurements were taken only when vertical displacement of the shoulders could be observed unambiguously. Inter-observer agreement was consistently between 90 and 95 percent. For each group of animals, data from different rearing conditions were lumped because no significant differences were detected. In addition, data for the wolves and wolfmalamute hybrids were combined because the two groups were indistinguishable.

The mean duration of bows performed at the beginning of sequences for the infant coyotes, wolves (and hybrids), beagles, and adult free-ranging dogs was $0.31,0.38,0.33$, and 0.32 second, respectively. Only the wolves differed significantly from the other groups $(F=2.93$, d.f. $=3,436, P<.05)$. Mean duration of bows performed during play bouts was on the average 0.03 to 0.07 second shorter than mean duration of bows at the beginning of play sequences, and there were no significant differences between the groups, although the bows performed by the wolves were slightly longer. The longer duration of the wolf bows may simply be due to the greater body weight of young wolves when compared to coyotes and beagles of the same age (16). For coyotes, beagles, and adult dogs, bows performed during an interaction showed significantly higher variability in duration than bows performed the beginning of sequences (Table 1). The greater variation in duration for bows performed during a sequence can be explained by the fact that these bows were preceded by a variety of different acts from which the individual went into the bow. On the other hand, the bows that occurred at the beginning of sequences almost always took place after the individual had been standing upright for a few seconds or as part of an approach.

All groups showed significantly less variability ["c" statistic (17), $P<.02$ ] in form when compared to duration. Furthermore, there were no significant differences in form between bows performed at the beginning of and during sequences, although in all cases bows performed during sequences were slightly more variable.

In addition to there being a high degree of stereotypy, especially in the form of the bow, it is important to stress two other findings: (i) there were no significant changes in the variability of bows performed by infants of different ages (18), and (ii) the first bows performed by individuals who had been hand-reared (19), and who had not previously interacted with another individual or seen a bow, did not differ either from subsequent bows performed by that "isolate" or from the first observed bows performed by individuals who had been group-reared. The observed stereotypy when coupled to these observations (and also to the lack of differences between older animals reared in different conditions) provide evidence that there is a strong genetic component underlying this behavioral pattern.

The data presented herein are the first (to my knowledge) of their kind for a mammalian display. When compared to data on invertebrates and other vertebrates $(5-7,13)$, the bow is seen to be an equally stereotyped display, even for the adult free-ranging dogs. That is, the bow is a "relatively fixed" or "modal" action pattern $(4,5)$. Indeed, there have been no analyses of signal form that have resulted in coefficients of variation equal, or nearly equal, to zero, and the implication of absolute (invariant) morphological rigidity in the term "fixed action pattern" is misleading (4-7) and apparently was not intended when the term was coined (20). 
It has been suggested that the most stereotyped motor coordinations are those that are important in locomotion and communication $(7,13)$. The bow is a locomotor intention movement which also has signal value. Many factors may select for stereotypy in signal form. Certainly, anatomical constraints may be operating $(9,21)$. In addition, if one analyzes the situations in which bows (and other play signals in other species) are used $(15,22-24)$, it is entirely plausible that the signal value of the bow was increased via selection for stereotypy. When animals engage in social play, actions from different contexts [for example, sexual, predatory, aggressive $(14,15,22-24)]$ are used. If play signals, such as the bow, are important in communicating play intention [that is, announcing that "what follows is play" $(14,15,22-24)$ ] and overriding the "meaning" of an aggressive signal (23), for example, then one would expect the play signal to be different from other types of signals and to be stereotyped so as to reduce ambiguity in meaning. Furthermore, there can also be a reduction in the number of contexts in which a signal is used $(2,12)$. In many mammals, signals that appear to function in the communication of play intent (i) are observed almost solely in the context of play $(15,22--24)$, (ii) are different from other types of social signals (22-24), and (iii) appear to be highly stereotyped. With respect to the canid play bow, these three criteria apply fully. In addition, it has been demonstrated in coyotes and other infant canids that signals that are used to solicit social play do function to reduce the likelihood of play grading into aggression $(23,25)$. In these (and possibly other) animals, there has been selection for signals that serve to communicate play intention, signals that have a "tonic" (26) effect in that they serve to change the probability distribution of subsequent responses by the recipient of the signal (23).

An analysis of the variability of individual motor acts does not provide any information about the ways in which these behaviors, stereotyped or not, are linked together to form continuous chains of behavior. It is possible for selection to operate on individual motor acts as well as on the order in which they are performed (27), and it has been suggested that behavioral sequences can serve display functions (28). That is, a sequence may function as a composite signal. For the infant canids used in this study, play sequences were more variable than nonplay sequences $(6,25)$. Therefore, it is possible that there are two sets of signals that are used in play. The first would be a play signal itself and the second would be the sequencing of the acts. In this way, the play intention of an individual could be communicated initially, and then the "play mood" could be maintained either by repeating play soliciting signals or by using the ongoing sequence as a play signal. In canids, play signals occur either in the beginning of play sequences or are randomly distributed throughout $(23,25)$. The proposed signal value of variable canid play sequences may be one reason for the observation that canid play signals seem to be more important in the initial soliciting of social play and less so for the maintenance of the "play mood" (23).

\section{References and Notes}

1. For reviews see T. A. Sebeok, Ed., Animal Communication (Indiana Univ. Press, Bloomington, 1968); How Animals Communicate (Indiana Univ. Press, Bloomington, 1977).

2. W. J. Smith, The Behavior of Communicating: An Ethological Approach (Harvard Univ. Press, Cambridge, Mass., 1977).

3. E. O. Wilson, Sociobiology: The New Synthesis (Harvard Univ. Press, Cambridge, Mass., 1975).

4. G. Barlow, in The Central Nervous System and Fish Behavior, D. Ingle, Ed. (Univ. of Chicago Press, Chicago, 1968), p. 217.

5. -----, in How Animals Communicate (1), p. 94.

6. M. Bekoff, in Quantitative Methods in the Study of Animal Behavior, B. A. Hazlett, Ed. (Academic Press, New York, 1977), p. 1.

7. W. Schleidt, Z. Tierpsychol. 36, 184 (1974).

8. G. Hausfater, Folia Primatol. 27, 41 (1977). 
9. I. Golani [Perspect. Ethol. 2, 69 (1976)] has proposed a variety of methods for measuring displays but has not studied variability in the form of "fast movements." He wrote that "their systematic description is essential for the understanding of the actual genesis of agonistic and play sequences" (p. 125).

10. S. Chevalier-Skolnikoff, Contrib. Primatol. 2, 1 (1974); G. M. Burghardt, in How Animals Communicate (1), p. 67; J.P. Hailman, Optical Signals: Animal Communication and Light (Indiana Univ. Press, Bloomington, 1977).

11. O. Heinroth, Verh. 5th Int. Ornithol. Kongr. Berlin 5, 589 (1911); J, S. Huxley, Proc. Zool. Soc. London (1914), p. 491; J. S. Huxley, Ed., Philos. Trans. R. Soc. London, Ser. B 251 (1966); C. O. Whitman, Carnegie Inst. Washington Publ. 257 (1919); K. Z. Lorenz, J. Ornithol. Suppl. 89, 194 (1941); P. Marler, Behaviour 11, 13 (1957); in Growing Points in Ethology, P. P. G. Bateson and R. A. Hinde, Eds. (Cambridge Univ. Press, New York, 1976), p. 239; N. Tinbergen, Behaviour 15, 1 (1959); D. Otte, Adv. Ecol. Syst. 5, 385 (1974); F. McKinney, in Function and Evolution in Behaviour, G. Baerends, C. Beer, A. Manning, Eds. (Oxford Univ. Press, New York, 1975), p. 331; C. G. Beer, in ibid., p. 16; Am. Zool. 17, 155 (1977).

12. T. D. Johnston, J. Theor. Biol. 57, 43 (1976).

13. R. H. Wiley, Behaviour 41, 129 (1973).

14. M. Bekoff, thesis, Washington University, St. Louis (1972).

15. ----, Am. Zool. 14, 323 (1974).

16. ---- and R. Jamieson, J. Mammal. 56, 685 (1975).

17. See R. Dawkins and M. Dawkins, Behaviour 45, 83 (1973) for formula for "c."

18. W. Schleidt and M. D. Shalter [Z. Tierpsychol. 33, 35 (1973)] and Wiley (13) also found no changes in variability with age in the birds that they studied [see also (6)].

19. The mean day of age for the first occurrence of bows was 26 for coyotes, 24 for wolves and wolf-dog hybrids, and 23 for beagles.

20. I. Eibli-Eibesfeldt, Ethology (Holt, Rinehart, \& Winston, New York, 1975).

21. A. Portmann, Animal Forms and Patterns (Faber \& Faber, London, 1952); D'Arcy Thompson, On Growth and Form (Cambridge Univ. Press, New York, 1961); R. B. Stein, K. G. Pearson, R. S. Smith, J. B. Redford, Eds., Control of Posture and Locomotion (Plenum, New York, 1974); R. E. Talbott, in ibid., p. 273; P. Lehner, in Coyotes: Behavior, Ecology, and Management, M. Bekoff, Ed. (Academtc Press, New York, in press). The greater variability observed in the bows of the adult dogs may be due to the fact that a heterogeneous population (different breeds and crosses) was studied. Since the vertical displacement of the shoulders is somewhat related to the length of the humerus, and in different breeds the length of this bone and its articulation with the scapula vary [M. Lyon, The Dog in Action (Howell, New York, 1952), pp. 102-103], greater variation would be expected when comparing a heterogeneous population to more homogeneous ones.

22. D. S. Sade, Am. J. Phys. Anthropol. 38, 537 (1973); M. Bekoff, Q. Rev. Biol. 47, 412 (1972); Perspect. Ethol. 2, 165 (1976); D. Symons, Am. Zool. 14, 317 (1974).

23. M. Bekoff, Semiotica 15, 231 (1975).

24. S. A. Altmann, in Social Communication Among Primates, S. A. Altmann, Ed. (Univ. of Chicago Press, Chicago, 1967), p. 325.

25. M. Bekoff and J. Moran, in preparation.

26. W. Schleidt, J. Theor. Biol. 42, 359 (1973).

27. D. J. McFarland, in Growing Points in Ethology (11), p. 55; R. M. Sibly and D. J. McFarland, Am. Nat. 110, 601 (1976); C. G. Beer, Ann. N.Y. Acad. Sci. 280, 413 (1976).

28. F. McKinney, Behaviour, Suppl. 7 (1961).

29. I thank numerous colleagues for reading an earlier draft of this report and the students in the Animal Behavior Laboratory who helped with filming and analysis. J. Moran helped with data compilation. This work was supported in part by PHS grants GM-01900 and ES-00139 and Biomedical Grant Support from the University of Colorado. 